\title{
The Rising Incidence of Gout; is Obesity to Blame?
}

\author{
Mamada C and Galanis N* \\ Department of Orthopaedics, Aristotle University of Thessaloniki, Greece
}

Submission: December 09, 2017; Published: February 19, 2018

*Corresponding author: Prof Nikiforos Galanis, Division of Sports Medicine, Department of Orthopaedics, Papageorgiou General Hospital, Medical School, Aristotle University of Thessaloniki, Kerasountos 6,55131, Thessaloniki, Greece, Tel: 00306977392229; Email: galanismed@gmail.com

\begin{abstract}
Once known as the disease of the ruling elite, gout's prevalencehas now reached epidemic proportions, and for this, researchers say, obesity is to blame. Obesity, Body Mass Index and visceral fat have a liner correlation with serum uric acid increase and can influence the age of gout development. A reduce of selected high-calorie foods and specific lifestyle changes can optimize not only gout symptoms, but most importantly can prevent its manifestation at first place. This Mini-Review states the arguments supporting this hypothesis and suggests that the metabolic nature of the disease should be in more consideration.
\end{abstract}

Keywords : Gout; Obesity; Uric acid; Nutrition; BMI; Visceral fat; Exercise; Lifestyle

Abbreviations : BMI: Body Mass Index

\section{Introduction}

Individuals that produce high levels of serum urine acid $(>7.0 \mathrm{mg} / \mathrm{dl})$ or are unable to shed urin acid superfluity tend to manifest a condition, known as hyperuricemia. At the $15 \%$ of the cases, if hyperuricemia continues for a long time it can lead to gout, a painful disease, caused by the buildup of uric acid crystals in the joints. However, the disease has now epidemic dimensions, and for this, researchers say, obesity is to blame [1-4].

\section{Obesity, C, Visceral Fat and Gout}

A study of 3.529 subjects in China showed that serum uric acid had liner correlation with obesity [5]. In particular, higher Body Mass Index (BMI) and waist circumference lead to an increase of visceral adiposity. This increase causes leptin production and higher insulin resistance [6]. The degree of insulin resistance correlates directly with the serum rate level and inversely with the renal rate clearance $[7,8]$. Leptin has been found to be a pathogenetic factor for hyperuricemia in obese patients and has been hypothesized to be the link between those two $[9,10]$. High BMI, also, increases blood pressure and serum triglycerides concentration, leading to hypertriglyceridemia, which promotes uric acid increment [6].

Furthermore, obese people are commonly characterized by a low muscle mass. A decrease of muscles can be associated with low-intensity chronic inflammation which dramatically increases uric acid in serum. That rise works as a defense mechanism for the organism in order to rebalance the intense oxidative stress resulting from muscle mass reduction [6].
However, until recently, it had not been proven that visceral fat increase is to blame for gout onset, rather than the amount of total fat [9]. In a study of 103 male patients and 204 age-matched healthy controls, visceral fat obesity was observed more frequently in patients with gout even in non-obese individuals. In addition, non-obese gout patients had hypertriglyceridemia and were pre-hypertensive more frequently than healthy controls [9]. Therefore, visceral fat obesity might more properly represent metabolic derangements rather than obesity itself. [9].

Obesity is not only a risk factor for gout incidents, but also for the age of potential gout development [10]. A study of 15.533 male participants, which began in 1989 [Campain Against Cancer and Heart Disease (CLUE II) study], have found that students who were obese at the age of 21 developed gout attacks approximately 11 years earlier than their non-obese counterparts. In the female adjusted analysis, provided by McAdams DeMarco's work, no differences were observed in the association of obesity and gout between the two sexes [10].

\section{Foods Inciting Both Gout and Obesity}

Recent studies have associated the consumption of selected high-calorie foods and drinks with both obesity and gout risk. A general summary of specific foods and drinks associated to high levels of serum uric acid and their caloriecontent is presented in (Table 1). Habitual consumption of purine-rich red meat, refined carbohydrates (such as white bread, pasta, sugar) and saturated fat are commonly included in an obese 
person's diet and according to studies, are highly associated with gout incidents by promoting insulin-resistance and increasing levels of plasma glucose, triglycarides, LDL-C and serum urate [11,12]. Highly processed foods (such as chips, snack foods, frozen dinners) and sugary beverages increase the risk of gout development, as well as the risk of obesity and type 2 diabetes [13]. Selected purine-rich seafood and vegetables, such as shrimps and spinach, should also be avoided since they can elevate uric acid levels whether the person is obese or not [14]. Concerning alcohol, a research investigating the association between alcohol calorie and overweight found that the odds of obesity were significantly higher with increased consumption of alcohol [15]. Meanwhile, alcohol is known to be a risk factor for gout development since ethanol ingestion accelerates ednosinetriphosphaye degradation into uric acid precursors $[16,17]$ which decreases urate excretion and increases urate production [17]. Beer has a greater effect on gout than any other type of alcohol since, alongside with ethanol, it contains high levels of guanosine, which is a highly absorbable purine [15]. All in all, a tempered consumption of the foods and drinks above can have a beneficial effect both on weight and gout control (Table 1).

Table 1: Summary of foods and drinks associated with serum uric acid increase and their calorie content, in descending order.

\begin{tabular}{|c|c|}
\hline 100gr of High-Calorie Foods & Calorie (kcal) \\
\hline Chips & 536,1 \\
\hline Sugar & 386,7 \\
\hline Lamp & 294 \\
\hline White bread & 264,6 \\
\hline Beef & 250,5 \\
\hline Pork & 242,1 \\
\hline Pasta & 131 \\
\hline Shrimp & 99 \\
\hline Spinach & 23 \\
\hline \multicolumn{2}{|c|}{ High-Calorie Drinks } \\
\hline Beer (425ml) & 215 \\
\hline Sugary Beverages (330ml) & 139 \\
\hline \multicolumn{2}{|c|}{ Wine (175ml) } \\
\hline
\end{tabular}

\section{Lifestyle Changes}

Prevention of gout disease is still rooted in lifestyle choices. In order to deteriorate gout symptoms due to obesity, the first step is to lose weight. According to recent studies, patients with gout disease who lost sixteen pounds by exercising reduced their uric acid levels approximately three points. In addition, exercise can mediate high blood pressure, cholesterol and type 2 diabetes which have been associated to gout disease according to a 2015 European study of 3.079 gout patients $[11,18]$. The substitution of red meat by vegetables lowers the risk of Gout development by $27 \%[19,20]$. Other important nutrients from vegetable sources, such as fiber or unsaturated fat, contribute to reducing long-term weight gain and lowering insulin resistance [11], which repeatedly has been shown to unbalance serum uric acid normal levels $[7,8]$.

\section{Conclusion}

Therapists have been occasionally treating gout as an inflammatory arthritis; hence, the metabolic nature of the disease requires a different approach which treats the patient and not the joint. A personalized diet combined with regular exercise may be a complementary treatment not only for the deterioration of gout symptoms, but most importantly, for the prevention of its manifestation. Both medical and nutritional studies have proven the correlation between obesity and serum uric acid levels, which is enough to actuate further investigations.

\section{References}

1. Roubenoff R, Klag MJ, Mead LA, Liang KY, Seidler AJ, et al. (1991) Incidence and risk factors for gout in white men. JAMA 266(21): 30043007.

2. Choi H, Atkinson K, Karlson E, Curhan G (2005) Obesity, Weight Change, Hypertension, Diuretic Use, and Risk of Gout in Men. Arch Intern Med 165(7): 742-748.

3. Bhole V, de Vera M, Rahman M, Krishnan E, Choi H (2010) Epidemiology of gout in women: Fifty-two-year follows up of a prospective cohort. Arthritis Rheum 62(4): 1069-1076.

4. Hall A, Barry P, Dawber T, McNamara P (1967) Epidemiolzogy of gout and hyperuricemia Am J Med 42(1): 27-37.

5. Duan Y, Wei L, Lijun Z, Ting Z, Linghong W, et al. (2015) Association between serum uric acid levels and obesity among university students (China). Nutr Hosp 31(6): 2407-2411.

6. de Oliveira E, Burini R (2012) High plasma uric acid concentration: causes and consequences Diabetol Metab Syndr 4: 12 .

7. Vuorinen-MH, Yki-Jarvinen $H$ (1994) Hyperuricemia and insulin resistance. J Clin Endocrinol Metab 78(1): 25-29.

8. Facchini F, Chen YD, Hollenbeck CB, Reaven GM (1991) Relationship between resistance to insulin-mediated glycose uptake, urinary uric acid clearance, and plasma uric acid concentration. JAMA 266(21): 3008-3011.

9. Fruehwald-SB, Peters A, Kern W, Beyer J, Pfutzner A (1999) Serum leptin is associated with serum uric acid concentration in humans. Metabolism 48(6): 677-680.

10. Lee J, Lee JY, Lee JH, Jung SM, Suh YS, et al. (2015) Visceral fat obesity is highly associated with primary gout in a metabolically obese but normal weighted population: a case control study Arthritis Res Ther 17: 79.

11. McAdams DeMarco M, Maynard J, Huizinga M, Baer A, Köttgen A, et al. (2011) Obesity and younger age at gout onset in a community-based cohort. Arthritis Care Res (Hoboken) 63(8): 1108-1114.

12. Arthritis.org (2017) How Fat Affects Gout . Arthritis Foundation.

13. Fam AG (2002) Gout, diet, and the insulin resistance syndrome. J Rheumatol 29(7): 1350-1355.

14. Ukgoutsociety.org (2017)

15. Mayo Clinic (2017) Gout diet: What's allowed, what's not.

16. Shelton, N, Knott C (2014) Association between Alcohol Calorie Intake and Overweight and Obesity in English Adults. Am J Public Health 104(4): 629-631. 
17. Puig JG, Fox IH (1984) Ethanol-induced activation of adenine nucleotide turnover. Evidence for a role of acetate. J Clin Invest 74: 936-941.

18. Eastmond CJ, Garton M, Robins S, Riddoch S (1995) The effects of alcoholic beverages on urate metabolism in gout sufferers. $\mathrm{Br}$ Rheumatol 34(8): 756-759.

19. Galanis N , Kleftouris G, Alafropatis I, Oral O, Tsiridis E, et al. (2016) Dietary Intakes and Nutritional Status of a Greek Team of Female

This work is licensed under Creative Commons Attribution 4.0 License

DOI: $10.19080 /$ NFSIJ.2018.05.555663
Volleyball Players. Arab Journal of Nutrition and Exercise (AJNE) 1(1): 1-14.

20. Mozaffarian D, Hao T, Rimm EB, Willett WC, Hu FB (2011) Changes in diet and lifestyle and long-term weight gain in women and men. $N$ Engl J Med 364(25): 2392-2404.

Your next submission with Juniper Publishers will reach you the below assets

- Quality Editorial service

- Swift Peer Review

- Reprints availability

- E-prints Service

- Manuscript Podcast for convenient understanding

- Global attainment for your research

- Manuscript accessibility in different formats

( Pdf, E-pub, Full Text, Audio)

- Unceasing customer service

Track the below URL for one-step submission https://juniperpublishers.com/online-submission.php 